Article

\title{
New Ikarugamycin Derivatives with Antifungal and Antibacterial Properties from Streptomyces zhaozhouensis
}

\section{Rodney Lacret*, Daniel Oves-Costales, Cristina Gómez, Caridad Díaz, Mercedes de la Cruz, Ignacio Pérez-Victoria, Francisca Vicente, Olga Genilloud and Fernando Reyes *}

Fundación MEDINA, Centro de Excelencia en Investigación de Medicamentos Innovadores en Andalucía, Avda. del Conocimiento 34, Armilla, Granada 18016, Spain;

E-Mails: daniel.oves@medinaandalucia.es (D.O.-C.); cristiga90@ gmail.com (C.G.); caridad.diaz@medinaandalucia.es (C.D.); mercedes.delacruz@medinaandalucia.es (M.C.); ignacio.perez-victoria@medinaandalucia.es (I.P.-V.); francisca.vicente@ medinaandalucia.es (F.V.); olga.genilloud@medinaandalucia.es (O.G.)

* Authors to whom correspondence should be addressed;

E-Mails: rodney.lacret@medinaandalucia.es (R.L); fernando.reyes@ medinaandalucia.es (F.R.); Tel.: +34-958993965 (R.L. \& F.R.); Fax: +34-958846710 (R.L. \& F.R.).

Academic Editor: Kirk R. Gustafson

Received: 13 November 2014 / Accepted: 16 December 2014 / Published: 29 December 2014

\begin{abstract}
A bioassay guided fractionation of the ethyl acetate extract from culture broths of the strain Streptomyces zhaozhouensis CA-185989 led to the isolation of three new polycyclic tetramic acid macrolactams (1-3) and four known compounds. All the new compounds were structurally related to the known Streptomyces metabolite ikarugamycin (4). Their structural elucidation was accomplished using a combination of electrospray-time of flight mass spectrometry (ESI-TOF MS) and 1D and 2D NMR analyses. Compounds 1-3 showed antifungal activity against Aspergillus fumigatus, Candida albicans and antibacterial activity against methicillin-resistant Staphylococcus aureus (MRSA).
\end{abstract}

Keywords: Streptomyces zhaozhouensis; ikarugamycin; polycyclic tetramate macrolactams; antifungal; antibacterial 


\section{Introduction}

The ocean has recently been shown to be an ecosystem with many unique forms of actinomycetes [1] whose distribution in the sea is largely unexplored and which have been proven to be a rich source for the discovery of new natural products with therapeutic potential [2,3]. It is well known that obtaining drugs from natural sources is a long and complex process, which has led to international, multidisciplinary projects with the goal of reducing the time between discovery of new biologically active microbial natural products and the development of new pharmaceuticals. One of such projects is the PharmaSea consortium, whose goals are the identification, study, and development of new antibacterial, antifungal, anti-inflammatory and neuroprotective compounds from marine microorganisms isolated from extreme environments. As part of this project, over 400 microorganisms, including strains from the extensively studied families Streptomycetaceae and Micromonosporaceae, as well as other minor taxa such as Micrococcaceae, Intrasporangiaceae, Microbacteriaceae, Nocardiopsaceae, Nocardiaceae and Mycobacteriaceae, were grown on carefully selected fermentation media, and their fermentation extracts were assayed against clinically relevant pathogenic microbial strains: Gram-positive bacteria (methicillin-resistant S. aureus, MRSA), Gram-negative bacteria (Escherichia coli and Pseudomonas aeruginosa), and fungi (A. fumigatus and C. albicans).

Growth inhibition of $A$. fumigatus, $C$. albicans and MRSA was observed in acetone extracts from fermentation broths of strain CA-185989, which upon 16S rRNA sequencing was found to be closely related to the recently described species Streptomyces zhaozhouensis NEAU-LZS-5(T) [4]. A bioassay-guided fractionation of extracts of this microorganism was carried out in order to isolate and identify the chemical constituents that were responsible for the observed activities. We report herein the isolation of three new polycyclic tetramic acid macrolactams (PTMs) (1-3) and four known compounds (4-7). Their structural elucidation was accomplished using a combination of spectroscopic techniques, including HRMS and extensive 1D and 2D NMR analyses. Compounds 1-3 possess new structures related to ikarugamycin (4), a PTM first isolated from Streptomyces phaeochromogenes sub-sp. ikaruganensis which showed strong antiprotozoal activity [5,6]. PTMs display a distinctive structure comprised of a macrolactam ring, a series of carbocyclic rings and a tetramic acid ring, and many of them possess antifungal properties [7-11].

\section{Results and Discussion}

\subsection{Isolation and Taxonomy of the Producing Microorganism}

The producing strain, CA-185989, was isolated from a marine sediment collected off-shore at two meters depth nearby Utonde, Equatorial Guinea. The BLASTN search [12] with the 16S rRNA gene sequence (1379 nt) indicated that the strain is closely related to the recently described S. zhaozhouensis NEAU-LZS-5(T) [4]. A phylogenetic tree generated using the neighbor-joining method corrected with the Jukes and Cantor algorithm [13,14] showed the relatedness of strain CA-185989 with S. zhaozhouensis NEAU-LZS-5(T) (99.93\% sequence similarity) and Streptomyces sedi YIM 65188(T) (99.56\% sequence similarity), a relatedness highly supported by the bootstrap values (Figure 1). The remaining closest members of the genus Streptomyces exhibited sequence similarities below $97.3 \%$. 


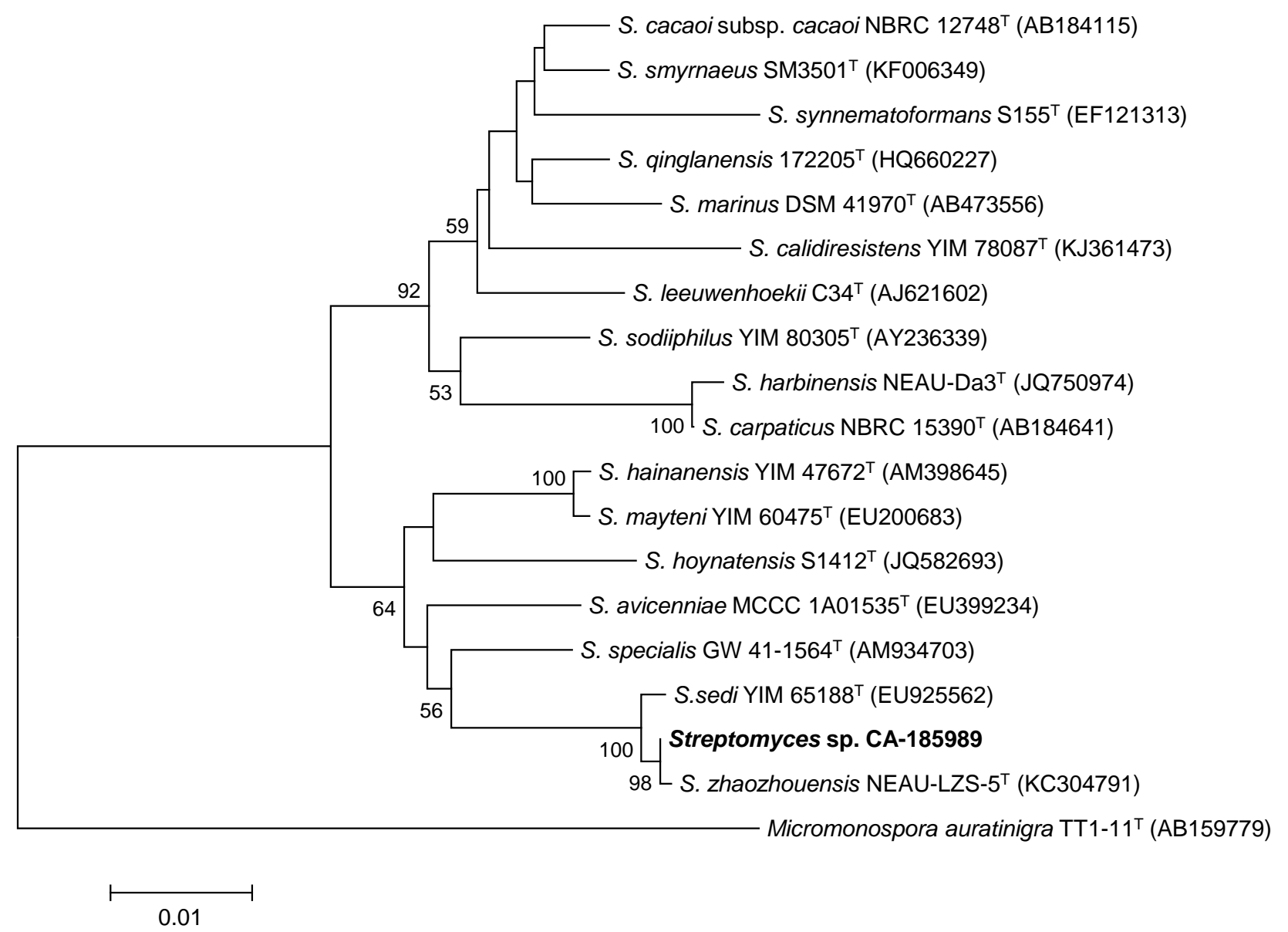

Figure 1. Neighbor-joining tree built with MEGA 6.06 based on nearly-complete $16 \mathrm{~S}$ rRNA gene sequences of CA-185989 and the closest type strains of the genus Streptomyces. Micromonospora auratinigra TT1-11(T) was employed as an out-group. The numbers at the nodes indicate bootstrap support (\%) based on NJ analysis of 1000 replicates; only values higher that $50 \%$ are shown. The scale bar indicates 0.01 substitutions per site.

\subsection{Bioassay-Guided Isolation}

The producing strain, S. zhaozhouensis CA-185989, was fermented at $28{ }^{\circ} \mathrm{C}$ in $1 \mathrm{~L}$ of APM9-modified medium during 6 days. Extraction with an equal volume of acetone and evaporation of the solvent afforded an aqueous crude extract (ACE), which was subsequently subjected to liquid-liquid extraction with ethyl acetate. LC-UV-MS analysis of the ACE (Figure 2) revealed the presence of ikarugamycin and some related PTMs which were not included in our internal microbial natural products library [15-17] and whose molecular formulae suggested the presence in the extract of new natural products. The resulting aqueous and organic extracts were assayed against $A$. fumigatus and $C$. albicans, with the organic extract being the most active one. This extract was chromatographed on silica gel using hexane/ethyl acetate mixtures of increasing polarity. 


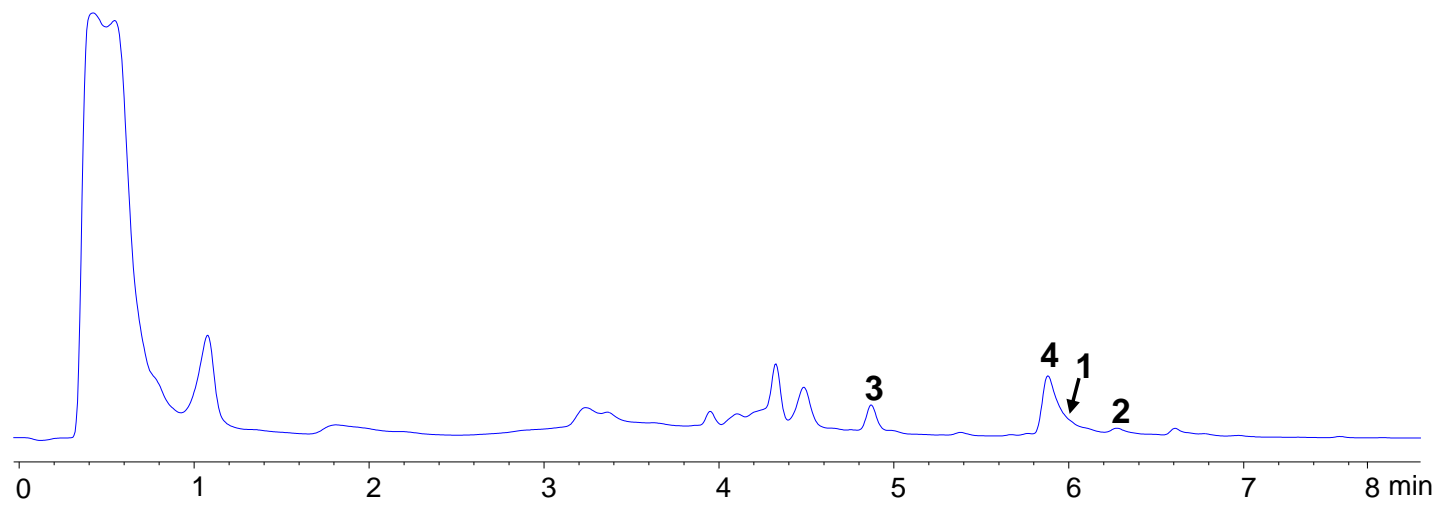

Figure 2. Chromatographic UV trace $(210 \mathrm{~nm})$ from the LC-UV-MS analysis of aqueous crude extract (ACE) where compounds 1-4 were detected.

Further chromatographic separation of bioactive fractions from this chromatography on a reversed phase $\mathrm{C} 8$ column using a gradient $\mathrm{CH}_{3} \mathrm{CN} / \mathrm{H}_{2} \mathrm{O}$ with $0.1 \%$ trifluoroacetic acid, allowed us to isolate seven compounds (1-7) (Figure 3). The spectroscopic data of 4-7 were identical to those previously reported for ikarugamycin (4) [5,6,18], MKN-003B (5) [19], $1 H$-indole-3-carboxaldehyde (6) [20] and phenylethanoic acid (7) [21]. All these compounds were isolated for the first time from the fermentation broths of $S$. zhaozhouensis. On the other hand, compounds 1-3 represent new natural products based on the structure of ikarugamycin (4).

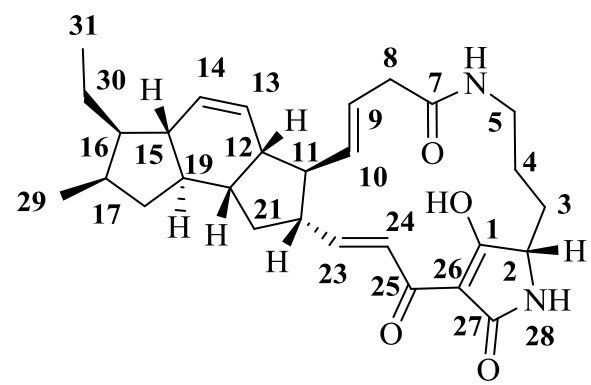

isoikarugamycin (1)<smiles>CC(C)(O)CCCCCC1C=CC(=O)O1</smiles>

MKN-003B (5)

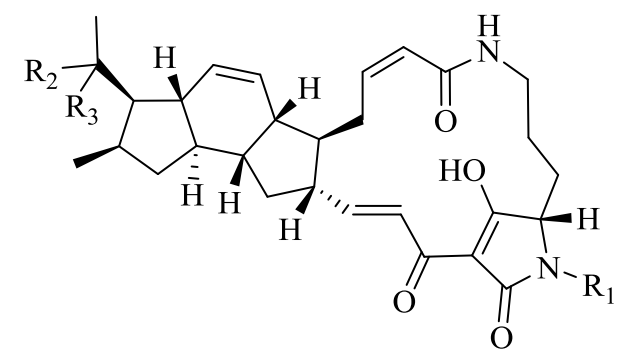

$\mathrm{R}_{1}=\mathrm{CH}_{3} \quad \mathrm{R}_{2}=\mathrm{R}_{3}=\mathrm{H} \quad 28-N$-methylikarugamycin (2) $\mathrm{R}_{1}=\mathrm{CH}_{3} \quad \mathrm{R}_{2}=\mathrm{R}_{3}=\mathrm{O} \quad$ 30-oxo-28- $N$-methylikarugamycin (3) $\mathrm{R}_{1}=\mathrm{H} \quad \mathrm{R}_{2}=\mathrm{R}_{3}=\mathrm{H} \quad$ ikarugamycin (4)<smiles>O=Cc1c[nH]c2ccccc12</smiles><smiles>O=C(O)Cc1ccccc1</smiles>

$1 H$-indole-3-carboxaldehyde (6)

Figure 3. Compounds isolated from culture broths of of Streptomyces zhaozhouensis.

\subsection{Structural Determination of the Compounds Isolated}

Compound 1 was isolated as a white amorphous solid. The ESI-TOF spectrum of this compound displayed a pseudomolecular ion at $m / z 479.2899$ (calc. for $[\mathrm{M}+\mathrm{H}]^{+} 479.2904$ ) corresponding to a molecular formula of $\mathrm{C}_{2} \mathrm{H}_{38} \mathrm{~N}_{2} \mathrm{O}_{4}$ and accounting for 12 degrees of unsaturation. The ${ }^{1} \mathrm{H}$ NMR 
spectrum (Table 1 and Figure S1) showed the presence of six olefinic protons at $\delta_{\mathrm{H}} 7.04(1 \mathrm{H}, \mathrm{d}, J=15.7$ Hz, H-24), 6.84 (1H, dd, $J=15.7,9.0 \mathrm{~Hz}, \mathrm{H}-23), 5.88$ (1H, d, $J=10.0 \mathrm{~Hz}, \mathrm{H}-14), 5.55$ (1H, d, $J=10.0$ Hz, H-13), 5.49 (1H, dd, $J=14.8,9.4 \mathrm{~Hz}, \mathrm{H}-9), 5.34(1 \mathrm{H}, \mathrm{dd}, J=14.8 \mathrm{~Hz}, 9.4 \mathrm{~Hz}, \mathrm{H}-10)$ and 5.83 $(1 \mathrm{H}, \mathrm{d}, J=10.0 \mathrm{~Hz}, \mathrm{H}-8)$. On the other hand, two methyl groups in the aliphatic region at $\delta 0.88(3 \mathrm{H}$, $\mathrm{d}, J=7.2 \mathrm{~Hz}, \mathrm{H}-29)$ and $0.93(3 \mathrm{H}, \mathrm{t}, J=7.2 \mathrm{~Hz}, \mathrm{H}-31)$ could also be distinguished. The ${ }^{13} \mathrm{C}$ NMR spectrum exhibited 29 signals and the multiplicity edited HSQC spectra suggested the presence of 5 quaternary, 15 methine, 7 methylene and 2 methyl carbons. The spectroscopic data indicated that compound 1 should be a polycyclic tetramic acid macrolactam with ikarugamycin skeleton and the molecular formula further suggested that this compound was an isomer of ikarugamycin (4) [18]. The major differences observed between the spectroscopic data of compound $\mathbf{1}$ and $\mathbf{4}$ were in agreement with the isomerization of one of the double bonds from the $\Delta^{8}$ to the $\Delta^{9}$ position. The $E$ configuration of the C-9/C-10 double bond was deduced from the coupling constant value of $14.8 \mathrm{~Hz}$ between $\mathrm{H}-9$ and $\mathrm{H}-10$. The HMBC experiment confirmed the position of double bond at $\Delta^{9}$, with correlations observed between $\mathrm{H}-8 \mathrm{a}(\delta 2.92)$ and $\mathrm{H}-8 \mathrm{~b}(\delta$ 3.05) with $\mathrm{C}-7(\delta 171.5), \mathrm{C}-9(\delta 127.7)$ and $\mathrm{C}-10$ $(\delta 133.9)$, as well as between $\mathrm{H}-11(\delta 1.88)$ and C-10 $(\delta 133.9)$, as shown in Figure 4.

Table 1. ${ }^{1} \mathrm{H}$ and ${ }^{13} \mathrm{C}$ NMR (500 and $125 \mathrm{MHz}$ in $\mathrm{CDCl}_{3}$ ) data for compounds $\mathbf{1}, \mathbf{2}$ and $\mathbf{3}$.

\begin{tabular}{|c|c|c|c|c|c|c|}
\hline \multirow[t]{2}{*}{ Position } & \multicolumn{2}{|c|}{ Isoikarugamycin (1) } & \multicolumn{2}{|c|}{ 28-N-Methylikarugamycin (2) } & \multicolumn{2}{|c|}{$\begin{array}{c}\text { 30-Oxo-28- } N \text {-Methyl } \\
\text { Ikarugamycin (3) }\end{array}$} \\
\hline & $\delta$ H, Mult., $(J$ Hz) & $\delta$ C, Mult. & $\delta$ H, Mult., $(J$ Hz $)$ & 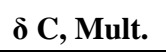 & 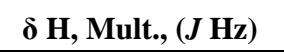 & $\delta$ C, Mult. \\
\hline 1 & & 196.7, C & & 195.3, C & & $195.2, \mathrm{C}$ \\
\hline 2 & 3.95 , br s & $61.4, \mathrm{CH}$ & $3.72, \mathrm{~d}(3.5)$ & $66.2, \mathrm{CH}$ & $3.71, \mathrm{~d}(4.0)$ & $66.3, \mathrm{CH}$ \\
\hline 3 & $1.92, \mathrm{~m} 2.02, \mathrm{~m}$ & 27.0, $\mathrm{CH}_{2}$ & $1.79, \mathrm{~d}(15.3) 2.14 \mathrm{~m}$ & $25.0, \mathrm{CH}_{2}$ & $1.79, \mathrm{~d}(15.8) 2.13 \mathrm{~m}$ & $24.9, \mathrm{CH}_{2}$ \\
\hline 4 & $1.10, \mathrm{~m} 1.67, \mathrm{~m}$ & $22.3, \mathrm{CH}_{2}$ & $1.13, \mathrm{~m} 1.47, \mathrm{~m}$ & $20.6, \mathrm{CH}_{2}$ & $1.10, \mathrm{~m} 1.47 \mathrm{~m}$ & $20.6, \mathrm{CH}_{2}$ \\
\hline 5 & $2.85, \mathrm{br} \mathrm{s} ; 3.46 \mathrm{br} \mathrm{s}$ & $38.4, \mathrm{CH}_{2}$ & $2.64, \mathrm{dd}(10.0,10.0) 3.69, \mathrm{br} \mathrm{s}$ & $38.9, \mathrm{CH}_{2}$ & $2.64, \mathrm{~m} \mathrm{3.64, \textrm {m }}$ & $38.7, \mathrm{CH}_{2}$ \\
\hline $6-\mathrm{NH}$ & 5.83 , br s & & 5.93 , br s & & 5.78, br s & \\
\hline 7 & & 171.5, C & & $166.6, \mathrm{C}$ & & 166.5, C \\
\hline 8 & $\begin{array}{c}2.92, \mathrm{dd}(14.8,9.4) \\
3.05, \mathrm{~d}(14.6)\end{array}$ & 41.3, $\mathrm{CH}_{2}$ & $5.83, \mathrm{dd}(11.3,1.3)$ & 123.7, $\mathrm{CH}$ & $5.82, \mathrm{~d}(11.3)$ & $123.8, \mathrm{CH}$ \\
\hline 9 & $5.49, \mathrm{dd}(14.8,9.4)$ & 127.7, $\mathrm{CH}$ & $6.08, \operatorname{ddd}(11.3,11.3,2.5)$ & 141.5, CH & $6.06, \mathrm{dd}(10.9,10.9)$ & $141.2, \mathrm{CH}$ \\
\hline 10 & $5.34, \mathrm{dd}(14.8,9.4)$ & $133.9, \mathrm{CH}$ & $2.39, \mathrm{dd}(11.3,2.5) 3.43, \mathrm{~m}$ & $25.4, \mathrm{CH}_{2}$ & $2.35, \mathrm{~m} \mathrm{3.47, \textrm {m }}$ & $25.2, \mathrm{CH}_{2}$ \\
\hline 11 & $1.88, \operatorname{dd}(9.4,9.4)$ & $56.1, \mathrm{CH}$ & $1.57, \mathrm{~m}$ & $48.2, \mathrm{CH}$ & $1.55, \mathrm{dd}(11.5,11.5)$ & $48.2, \mathrm{CH}$ \\
\hline 12 & $2.30, \mathrm{~m}$ & $47.9, \mathrm{CH}$ & $2.50, \mathrm{~m}$ & $42.8, \mathrm{CH}$ & $2.51 \mathrm{~m}$ & $42.5, \mathrm{CH}$ \\
\hline 13 & $5.55, \mathrm{~d}(10.0)$ & $128.4, \mathrm{CH}$ & $5.68, \mathrm{dd}(10.0,2.0)$ & $128.0, \mathrm{CH}$ & $5.68, \mathrm{dd}(10.0,2.0)$ & 128.6, $\mathrm{CH}$ \\
\hline 14 & $5.88, \mathrm{~d}(10.0)$ & $130.9, \mathrm{CH}$ & $5.94, \mathrm{~d}(10.0)$ & 131.6, $\mathrm{CH}$ & $5.74, \mathrm{~d}(10.0)$ & $130.0, \mathrm{CH}$ \\
\hline 15 & $1.54, \mathrm{~m}$ & $47.0, \mathrm{CH}$ & $1.57, \mathrm{~m}$ & $46.9, \mathrm{CH}$ & $2.37, \mathrm{~m}$ & $43.0, \mathrm{CH}$ \\
\hline 16 & $1.35, \mathrm{~m}$ & $46.9, \mathrm{CH}$ & $1.37, \mathrm{~m}$ & $47.2, \mathrm{CH}$ & $2.68, \mathrm{~m}$ & $58.8, \mathrm{CH}$ \\
\hline 17 & $2.26, \mathrm{~m}$ & $33.0, \mathrm{CH}$ & 2.26 , ddd $(7.4,7.4,7.4)$ & $33.0, \mathrm{CH}$ & $2.62, \mathrm{~m}$ & $33.7, \mathrm{CH}$ \\
\hline 18 & $\begin{array}{l}0.69, \text { ddd }(12.0, \\
12.0,6.8) 2.11, \mathrm{~m}\end{array}$ & $38.4, \mathrm{CH}_{2}$ & $\begin{array}{c}0.69, \text { ddd }(12.0,12.0,6.8) \\
2.08, \mathrm{~m}\end{array}$ & $38.4, \mathrm{CH}_{2}$ & $0.82, \mathrm{~m} \mathrm{2.15, \textrm {m }}$ & $38.9, \mathrm{CH}_{2}$ \\
\hline 19 & $1.13, \mathrm{~m}$ & 48.7, CH & $1.16, \mathrm{~m}$ & $48.8, \mathrm{CH}$ & $1.20, \mathrm{~m}$ & 47.7, CH \\
\hline 20 & $2.10, \mathrm{~m}$ & $42.3, \mathrm{CH}$ & $2.08, \mathrm{~m}$ & $41.7, \mathrm{CH}$ & $2.13, \mathrm{~m}$ & $41.0, \mathrm{CH}$ \\
\hline 21 & $1.37, \mathrm{~m} \mathrm{2.30, \textrm {m }}$ & 37.1, $\mathrm{CH}_{2}$ & $1.24, \mathrm{~m} \mathrm{2.16, \textrm {m }}$ & 36.7, $\mathrm{CH}_{2}$ & $1.23, \mathrm{~m} \mathrm{2.15, \textrm {m }}$ & $36.5, \mathrm{CH}_{2}$ \\
\hline 22 & $2.55, \mathrm{~m}$ & $50.6, \mathrm{CH}$ & $2.49, \mathrm{~m}$ & $49.5, \mathrm{CH}$ & $2.51, \mathrm{~m}$ & 49.3, $\mathrm{CH}$ \\
\hline
\end{tabular}


Table 1. Cont.

\begin{tabular}{ccccccc}
\hline 23 & $6.84, \mathrm{dd}(15.7,9.0)$ & $152.6, \mathrm{CH}$ & $6.75, \mathrm{dd}(15.5,10.3)$ & $153.2, \mathrm{CH}$ & $6.72, \mathrm{dd}(15.4,10.2)$ & $151.7, \mathrm{CH}$ \\
24 & $7.04, \mathrm{~d}(15.7)$ & $123.2, \mathrm{CH}$ & $7.12, \mathrm{~d}(15.5)$ & $122.2, \mathrm{CH}$ & $7.12, \mathrm{~d}(15.5)$ & $122.4, \mathrm{CH}$ \\
25 & & $174.7, \mathrm{C}$ & & $172.9, \mathrm{C}$ & & $172.9, \mathrm{C}$ \\
26 & & $100.0, \mathrm{C}$ & & $100.7, \mathrm{C}$ & & $100.8, \mathrm{C}$ \\
27 & & $175.5, \mathrm{C}$ & & $173.4, \mathrm{C}$ & & $173.4, \mathrm{C}$ \\
$28-\mathrm{NR}_{1}$ & & & $2.93, \mathrm{~s}$ & $26.3, \mathrm{CH}_{3}$ & $2.93, \mathrm{~s}$ & $26.3, \mathrm{CH}_{3}$ \\
29 & $0.88, \mathrm{~d}(7.2)$ & $17.7, \mathrm{CH}_{3}$ & $0.87, \mathrm{~d}(7.2)$ & $17.7, \mathrm{CH}_{3}$ & $0.85, \mathrm{~d}(7.0)$ & $18.8, \mathrm{CH}_{3}$ \\
30 & $1.35, \mathrm{~m} \mathrm{1.46, \textrm {m }}$ & $21.6, \mathrm{CH}_{2}$ & $1.35, \mathrm{~m} \mathrm{1.46, \textrm {m }}$ & $21.6, \mathrm{CH}_{2}$ & & $210.2, \mathrm{C}$ \\
31 & $0.93, \mathrm{t}(7.2)$ & $13.2, \mathrm{CH}_{3}$ & $0.93, \mathrm{t}(7.2)$ & $13.4, \mathrm{CH}_{3}$ & $2.16, \mathrm{~s}$ & $31.4, \mathrm{CH}_{3}$ \\
\hline
\end{tabular}

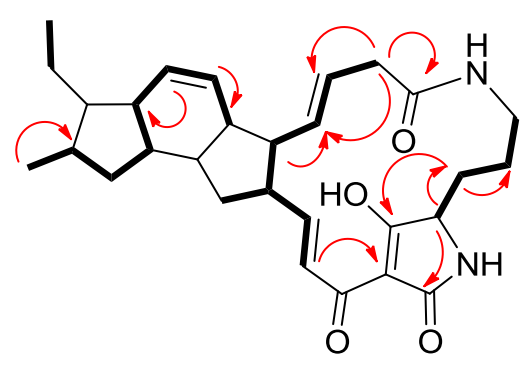

1

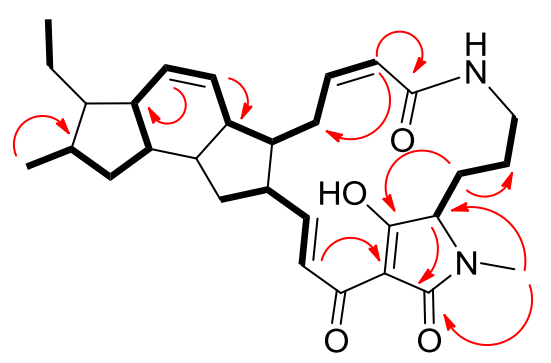

2

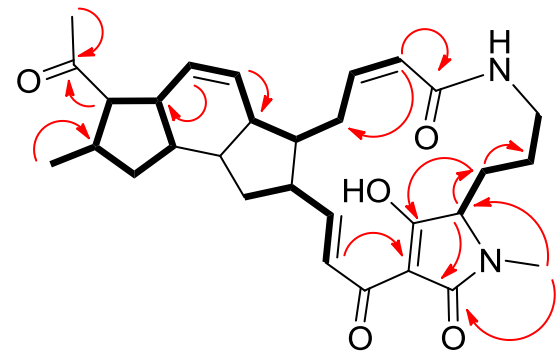

3

- COSY

$\longrightarrow \mathrm{HMBC}$

Figure 4. Key COSY and HMBC correlations observed in the spectra of compounds 1-3.

The relative configuration of $\mathbf{1}$ was deduced to be the same as that of ikarugamycin (4) on the basis of the key NOESY correlations observed for compound 1 (Figures 5, S5 and S6) and the common biogenetic origin of both molecules. It has been recently proposed that PTMs share a common biosynthetic pathway [18,22]. A biosynthesis route through an electrophilic addition from the corresponding intermediate $\mathbf{8}$ was proposed for ikarugamycin (4) [18]. Similarly, the biosynthesis of compound 1 could be explained by the deprotonation of a water molecule by the C-7/C-8 enol transient intermediate, which also justifies the $E$ the stereochemistry observed for the $\Delta^{9,10}$ double bond (Figure 6). The isolation of isoikarugamycin in the current work represents the first experimental evidence validating the proposed ikarugamycin biosynthetic pathway via intermediate $\mathbf{8}$. This is the first time that compound $\mathbf{1}$ has been isolated from a natural source and we have given it the trivial name isoikarugamycin.

Compound 2 was obtained as a white amorphous solid. Its molecular formula was assigned as $\mathrm{C}_{30} \mathrm{H}_{40} \mathrm{~N}_{2} \mathrm{O}_{4}$ by ESI-TOFMS ( $m / z$ 493.3063, calc. for $\left.[\mathrm{M}+\mathrm{H}]^{+} 493.3061\right)$. The ${ }^{1} \mathrm{H}$ NMR and ${ }^{13} \mathrm{C}$ NMR spectra of 2 (Table 1 and Figure S2) were very similar to those of 4 (Figure S4 and Table S1, Supporting Information) indicating that it was a derivative of ikarugamycin. The singlet at $\delta 2.93(3 \mathrm{H}, \mathrm{s})$ was assigned to an $\mathrm{N}$-methyl group, being the major difference with respect to the spectrum of ikarugamycin, and indicating that compound $\mathbf{2}$ should be an $N$-methyl polycyclic tetramic acid macrolactam with ikarugamycin skeleton $[18,23]$. The ${ }^{13} \mathrm{C}$ NMR spectrum exhibited 30 signals and the multiplicity edited HSQC spectra confirmed the presence of 5 quaternary, 15 methine, 7 methylene and 
3 methyl carbons. The correlations in the HMBC experiment (Figure 4) between the $N$-methyl group at $\delta$ 2.93 and the signals at $\delta 66.2(\mathrm{C}-3), 100.7$ (C-26) and 174.1 (C-27) confirmed the position of the $\mathrm{N}$-methyl group at $\mathrm{N}-28$ and led us to propose the structure depicted in Figure 3 . The relative configuration of $\mathbf{2}$ is proposed to be identical to that reported for ikarugamycin (4) on the basis of NOESY correlations observed for compound 2 (see Figure S5), and the pattern of $J$ values observed in its ${ }^{1} \mathrm{H}$ NMR spectrum. Compound 2 has therefore the structure of $28-N$-methylikarugamycin. This molecule has been reported previously in a patent as a synthetic derivative of ikarugamycin [24]. This is the first report on the isolation of $\mathbf{2}$ from a natural source.

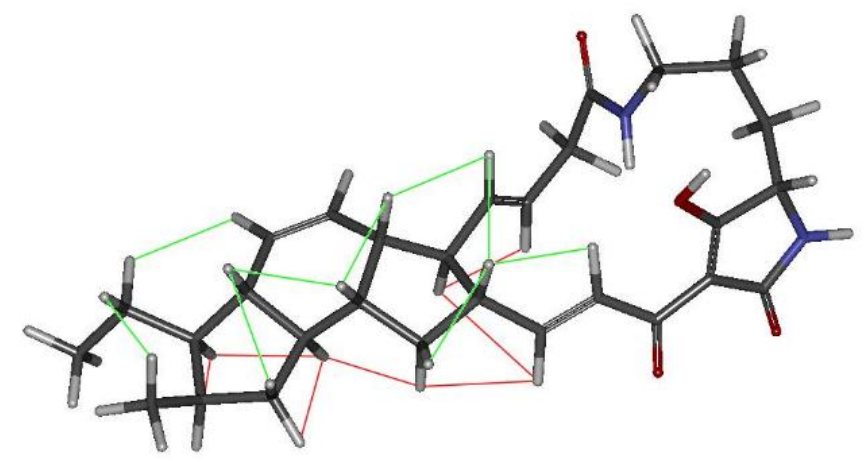

Figure 5. Molecular model of compound 1 showing the key observed NOESY correlations. The protons in $\beta$ orientation (relative to the fused tricycle pseudoplane according to the 2D structure scketches) displaying mutual correlation are connected by green lines while red lines are employed for those in $\alpha$ orientation.

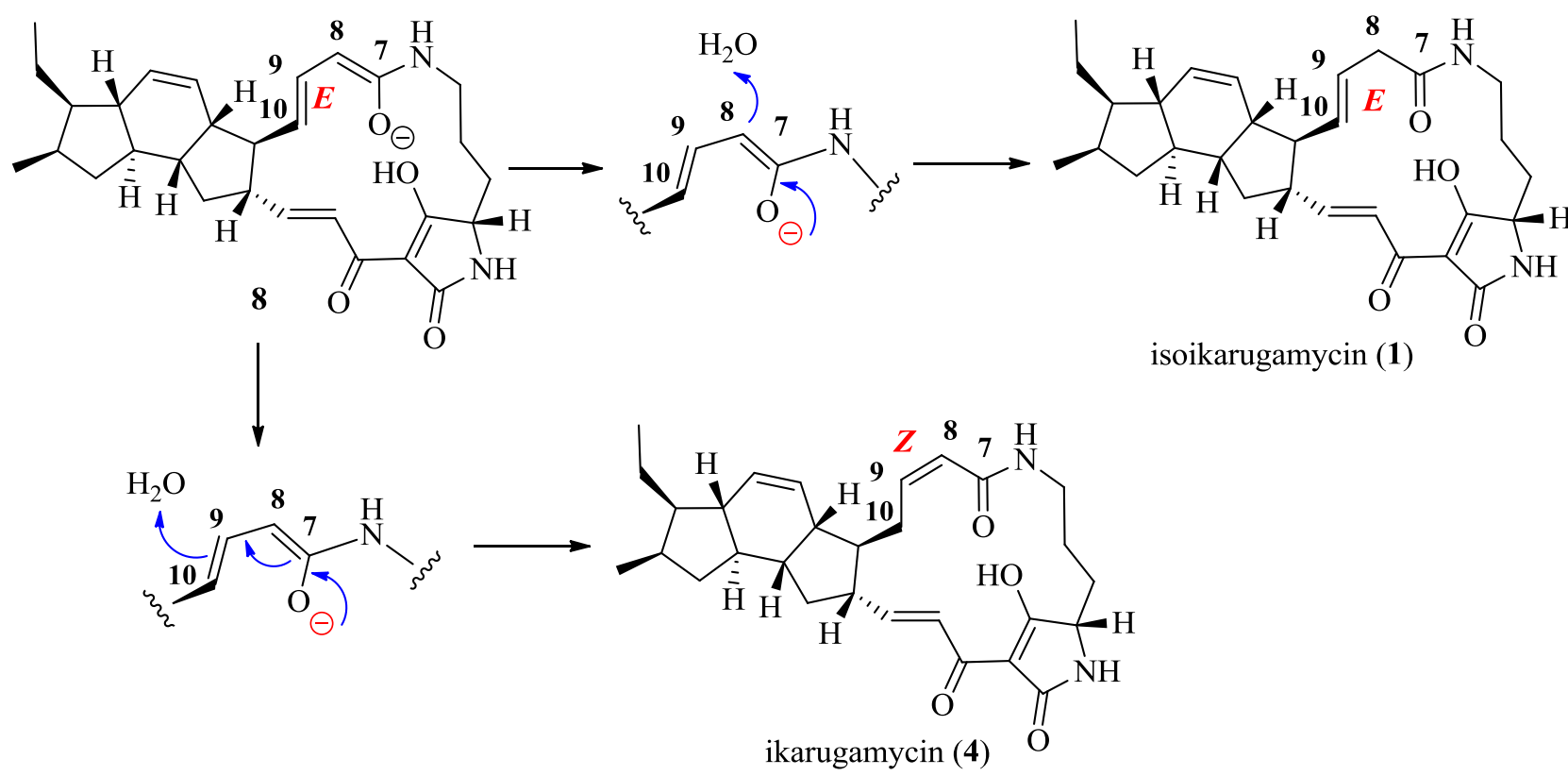

Figure 6. Proposed biosynthetic scheme for compound 1.

The molecular formula of compound $\boldsymbol{3}$ was established as $\mathrm{C}_{30} \mathrm{H}_{38} \mathrm{~N}_{2} \mathrm{O}_{5}$ by ESI-TOFMS $\left(m / z\right.$ 507.2859, calc. for $[\mathrm{M}+\mathrm{H}]^{+}$507.2854). Its ${ }^{1} \mathrm{H}$ NMR spectrum (Table 1, Figure S3) was very similar to that of compound $\mathbf{2}$, indicating that $\mathbf{3}$ was a derivative of $28-N$-methylikarugamycin. The 
most significant difference between the two spectra was the chemical shift and multiplicity of the signals due to protons of one of the methyl groups at $\delta 2.16(3 \mathrm{H}, \mathrm{s})$. NMR data suggested that these two compounds differed in the presence of one carbonyl group in $\mathbf{3}$, which must be located at C-30. The ${ }^{13} \mathrm{C}$ NMR spectrum contained 30 signals: 3 methyl, 6 methylene, 15 methine and 6 quaternary carbons, according to an HSQC experiment. Four of the quaternary carbons at $\delta 166.5,172.9,173.4$ and 210.2 corresponded to carbonyl groups. Correlations observed in the HMBC experiment (Figure 4) between the methyl group at $\delta 2.16(\mathrm{H}-31)$ and $\mathrm{H}-29$ with the signal at $\delta 210.2$ confirmed the presence of a ketone carbonyl group at C-30. On the basis of these data the structure suggested for this compound was 30-oxo-28- $N$-methylikarugamycin as shown in Figure 3. This is the first time that compound $\mathbf{3}$ has been isolated from a natural source. The $N$-demethyl derivative of $\mathbf{3}$, clifednamide A, was recently found in cultures of an environmental Streptomyces sp. following a targeted polymerase chain reaction (PCR)-targeted screening approach [25].

\subsection{Antifungal and Antibacterial Activities}

The antifungal and antibacterial properties of compounds 1-7 were evaluated against methicillin-MRSA, E. coli, C. albicans and A. fumigatus (Table 2). Regarding antibacterial activity, isoikarugamycin (1), 28- $\mathrm{N}$-methylikaguramycin (2) and ikarugamycin (4), showed strong inhibition of MRSA growth with MIC value ranges of 2-4, 1-2 and 2-4 $\mu \mathrm{g} / \mathrm{mL}$, respectively, while 30-oxo-28- $N$ methylikarugamycin (3) showed weaker activity against MRSA with a MIC range of 32-64 $\mu \mathrm{g} / \mathrm{mL}$. None of the compounds displayed activity against $E$. coli when tested at concentrations of $64 \mu \mathrm{g} / \mathrm{mL}$. Concerning antifungal properties, isoikarugamycin (1) inhibited the growth of $C$. albicans and A. fumigatus with MIC value ranges of $2-4$ and $4-8 \mu \mathrm{g} / \mathrm{mL}$, respectively, whereas $28-N$-methylikaguramycin (2) and ikarugamycin (4) showed a MIC value of $4 \mu \mathrm{g} / \mathrm{mL}$ against $C$. albicans and a MIC value range of 4-8 $\mu \mathrm{g} / \mathrm{mL}$ against $A$. fumigatus. 30-oxo-28- $N$-methylikarugamycin 3 did not inhibit the growth of C. albicans or A. fumigatus when assayed at a concentration of $64 \mu \mathrm{g} / \mathrm{mL}$. Compounds 5-7 did not inhibit the growth of any of the microorganisms employed in the panel when tested at a concentration of $64 \mu \mathrm{g} / \mathrm{mL}$.

Table 2. Antibacterial and antifungal activities of compounds 1-7.

\begin{tabular}{ccccc}
\hline \multirow{2}{*}{ Compound } & \multicolumn{4}{c}{ MIC, $\boldsymbol{\mu g} / \mathbf{m L}$} \\
\cline { 2 - 5 } & $\begin{array}{c}\text { MRSA } \\
\text { MB5393 }\end{array}$ & $\begin{array}{c}\text { C. albicans } \\
\text { MY1055 }\end{array}$ & $\begin{array}{c}\text { A. fumigatus } \\
\text { ATCC46645 }\end{array}$ & E. coli MB2884 \\
\hline isoikarugamycin (1) & $2-4$ & $2-4$ & $4-8$ & $>64$ \\
28- $N$-methylikaguramycin (2) & $1-2$ & 4 & $4-8$ & $>64$ \\
30-oxo-28- $N$-methylikarugamycin (3) & $32-64$ & $>64$ & $>64$ & $>64$ \\
Ikarugamycin (4) & $2-4$ & 4 & $4-8$ & $>64$ \\
MKN-003B (5) & $>64$ & $>64$ & $>64$ & $>64$ \\
1H-indole-3-carboxaldehyde (6) & $>64$ & $>64$ & $>64$ & $>64$ \\
Phenylethanoic acid (7) & $>64$ & $>64$ & $>64$ & $>64$ \\
\hline
\end{tabular}




\section{Experimental Section}

\subsection{General Experimental Procedures}

Optical rotations were measured with a Jasco P-2000 polarimeter (JASCO Corporation, Tokyo, Japan). IR spectra were measured with a JASCO FT/IR-4100 spectrometer (JASCO Corporation) equipped with a PIKE MIRacle ${ }^{\mathrm{TM}}$ (JASCO Corporation) single reflection ATR accessory. NMR spectra were recorded on a Bruker Avance III spectrometer (Bruker Biospin, Fällanden, Switzerland) (500 and $125 \mathrm{MHz}$ for ${ }^{1} \mathrm{H}$ and ${ }^{13} \mathrm{C} \mathrm{NMR}$, respectively) equipped with a $1.7 \mathrm{~mm} \mathrm{~mm} \mathrm{TCI}$ MicroCryoProbe $^{\mathrm{TM}}$ (Bruker Biospin). Chemical shifts were reported in ppm using the signals of the residual solvents as internal references $\left(\delta_{\mathrm{H}} 7.25\right.$ and $\delta_{\mathrm{C}} 77.0$ for $\left.\mathrm{CDCl}_{3}\right)$. LC-UV-MS analysis was performed on an Agilent 1100 (Agilent Tehcnologies, Santa Clara, CA, USA) single quadrupole LC-MS system. ESI-TOF and MS/MS spectra were acquired using a Bruker maXis QTOF (Bruker Daltonik GmbH, Bremen, Germany) mass spectrometer coupled to an Agilent 1200 LC (Agilent Technologies, Waldbronn, Germany). Acetone used for extraction was analytical grade. Solvents employed for isolation were HPLC grade. Molecular models were generated in Chem3D Pro 12.0 (CambridgeSoft, PerkinElmer Informatics, Waltham, MA, USA). Torsional angles of the C11-C10 and C22-C23 bonds outside the fused tricycle were first adjusted manually to reasonable values which could explain the key NOEs observed for protons H-9, H-10, H-23 and H-24. Those starting structures were minimized by molecular mechanics with the MM2 force field using as gradient convergence criteria an RMS value of 0.001 . The resulting models were in agreement with that reported for butremycin [23] and perfectly accounted for all the key NOEs observed in the spectra.

\subsection{Fermentation of the Producing Microorganism}

A 1 liter fermentation of strain CA-185989 was generated as follows: a seed culture of the strain was obtained by inoculating three $50 \mathrm{~mL}$ tubes each containing $14 \mathrm{~mL}$ of ATCC-2-M medium (soluble starch $20 \mathrm{~g} / \mathrm{L}$, glucose $10 \mathrm{~g} / \mathrm{L}$, NZ Amine Type E $5 \mathrm{~g} / \mathrm{L}$, meat extract $3 \mathrm{~g} / \mathrm{L}$, peptone $5 \mathrm{~g} / \mathrm{L}$, yeast extract $5 \mathrm{~g} / \mathrm{L}$, sea salts $30 \mathrm{~g} / \mathrm{L}$, calcium carbonate $1 \mathrm{~g} / \mathrm{L}, \mathrm{pH} 7$ ) with $0.7 \mathrm{~mL}$ of a freshly thawed inoculum stock of the producing strain. Tubes were incubated in a rotary shaker at $28{ }^{\circ} \mathrm{C}, 70 \%$ relative humidity and $220 \mathrm{rpm}$ for about $96 \mathrm{~h}$. This fresh inoculum was employed to inoculate twenty $250 \mathrm{~mL}$ flasks, each containing $50 \mathrm{~mL}$ of APM9-modifed medium $(2.5 \% \mathrm{v} / \mathrm{v})$ (glucose $50 \mathrm{~g} / \mathrm{L}$, soluble starch $12 \mathrm{~g} / \mathrm{L}$, soy flour $30 \mathrm{~g} / \mathrm{L}, \mathrm{CoCl}_{2} \cdot 6 \mathrm{H}_{2} \mathrm{O} 2 \mathrm{mg} / \mathrm{L}$, sea salts $30 \mathrm{~g} / \mathrm{L}$, calcium carbonate $7 \mathrm{~g} / \mathrm{L}, \mathrm{pH}$ 7). The inoculated flasks were incubated in a rotary shaker at $28{ }^{\circ} \mathrm{C}, 70 \%$ relative humidity and $220 \mathrm{rpm}$ for 6 days before harvesting.

\subsection{Extraction and Bioassay Guided Isolation}

The scaled-up fermentation broth $(1 \mathrm{~L})$ was extracted with acetone $(1 \mathrm{~L})$ under continuous shaking at $220 \mathrm{rpm}$ for $2 \mathrm{~h}$. The mycelium was separated by filtration and the supernatant ( $c a$. $2 \mathrm{~L}$ ) was concentrated to $1 \mathrm{~L}$ under reduced pressure. This aqueous residue was extracted with ethyl acetate (A). $10 \mathrm{~mL}$ of the resulting aqueous layer were dried under reduced pressure (B). Bioactivity against A. fumigatus, C. albicans and MRSA was confirmed in the ethyl acetate extract. This extract (A, $3.94 \mathrm{~g})$ 
was chromatographed on $\mathrm{SiO}_{2}$ using mixtures of hexane/EtOAc of increasing polarity and methanol to afford ten fractions: A1-A10. Fractions A4 (0.020 g), A8 (0.75 g) and A10 (1.05 g) were the most active against $A$. fumigatus and $C$. albicans.

Fraction A4 (0.020 g, hexane/EtOAc, 1:1) was subjected to fractionation by reversed-phase semipreparative HPLC (column Agilent Zorbax RX-C8, $9.4 \times 250 \mathrm{~mm}, 7 \mu \mathrm{m} ; 3 \mathrm{~mL} \cdot \mathrm{min}^{-1}$, UV detection at 210 and $280 \mathrm{~nm}$ ) with a linear gradient of $\mathrm{CH}_{3} \mathrm{CN} / \mathrm{H}_{2} \mathrm{O}$ with $0.1 \%$ trifluoroacetic acid from $10 \%$ to $40 \% \mathrm{CH}_{3} \mathrm{CN}$ over $36 \mathrm{~min}$ yielding $6\left(1.2 \mathrm{mg}, t_{\mathrm{R}} 28 \mathrm{~min}\right)$ and 7 (1.8 $\left.\mathrm{mg}, t_{\mathrm{R}} 32 \mathrm{~min}\right)$.

Fraction A8 (0.750 g, hexane/EtOAc, 1:4-1:9) was selected for further fractionation by reversed-phase preparative HPLC (column Agilent Zorbax SB-C8, $21.2 \times 250 \mathrm{~mm}, 7 \mu \mathrm{m} ; 20 \mathrm{~mL} \cdot \mathrm{min}^{-1}$, UV detection at 210 and $280 \mathrm{~nm}$ ) with a linear gradient of $\mathrm{CH}_{3} \mathrm{CN} / \mathrm{H}_{2} \mathrm{O}$ with $0.1 \%$ trifluoroacetic acid, from $20 \%$ to $85 \% \mathrm{CH}_{3} \mathrm{CN}$ over $45 \mathrm{~min}$, to afford seven subfractions: A8A-A8G. Subfractions A8D, A8E, A8F and A8G were the most active against A. fumigatus and C. albicans. Subfraction A8D was chromatographed on Sephadex LH-20 using mixtures of chloroform/methanol (2:1) affording four fractions. The third fraction was purified by reverse-phase semipreparative HPLC (column Agilent Zorbax RX-C8, $9.4 \times 250 \mathrm{~mm}, 7 \mu \mathrm{m} ; 3 \mathrm{~mL} \cdot \mathrm{min}^{-1}$, UV detection at 210 and $280 \mathrm{~nm}$ ) with an isocratic solvent system of $\mathrm{CH}_{3} \mathrm{CN} / \mathrm{H}_{2} \mathrm{O}(45 / 55)$ with $0.1 \%$ trifluoroacetic acid to yield 3 (3.2 mg, $\left.t_{\mathrm{R}} 27 \mathrm{~min}\right)$. Subfractions A8E and $\mathrm{A} 8 \mathrm{G}$ were further purified by reverse-phase semipreparative HPLC (column Agilent Zorbax RX$\mathrm{C} 8,9.4 \times 250 \mathrm{~mm}, 7 \mu \mathrm{m} ; 3 \mathrm{~mL} \cdot \mathrm{min}^{-1}$, UV detection at 210 and $280 \mathrm{~nm}$ ) with linear gradient of $\mathrm{CH}_{3} \mathrm{CN} / \mathrm{H}_{2} \mathrm{O}$ with $0.1 \%$ trifluoroacetic acid, from $50 \%$ to $80 \% \mathrm{CH}_{3} \mathrm{CN}$ yielding 4 (2.2 $\left.\mathrm{mg}, t_{\mathrm{R}} 18 \mathrm{~min}\right)$ and $2\left(2.2 \mathrm{mg}, t_{\mathrm{R}} 25 \mathrm{~min}\right)$, respectively. Subfraction A8F was subjected to CC on Sephadex LH-20 using a mixture of $\mathrm{CHCl}_{3} / \mathrm{MeOH}$ (2:1). Further purification by $\mathrm{C}-8$ HPLC under the same chromatographic conditions, yielded 4 ( $\left.3.2 \mathrm{mg}, t_{\mathrm{R}} 25 \mathrm{~min}\right)$ and $\mathbf{1}\left(0.8 \mathrm{mg}, t_{\mathrm{R}} 26 \mathrm{~min}\right)$.

Fraction A10 $(0.120 \mathrm{~g}, \mathrm{MeOH})$ was subjected to fractionation by reversed-phase preparative HPLC (column Agilent Zorbax SB-C8, $21.2 \times 250 \mathrm{~mm}, 7 \mu \mathrm{m} ; 20 \mathrm{~mL} \cdot \mathrm{min}^{-1}$, UV detection at 210 and $280 \mathrm{~nm}$ ) with linear gradient $\mathrm{CH}_{3} \mathrm{CN} / \mathrm{H}_{2} \mathrm{O}$ with $0.1 \%$ trifluoroacetic acid from $30 \%$ to $60 \% \mathrm{CH}_{3} \mathrm{CN}$, yielding 5 (2.5 mg, $\left.t_{\mathrm{R}} 11 \mathrm{~min}\right)$ and 4 (3.5 mg, $\left.t_{\mathrm{R}} 35 \mathrm{~min}\right)$.

Isoikarugamycin (1): White amorphous solid; $[\alpha]^{25} \mathrm{D}+362.1$ (c 0.085, $\mathrm{CHCl}_{3}$ ); UV (DAD) $\lambda \max 228$, $323 \mathrm{~nm}$; IR (ATR) $v_{\max } 3319,2955,1715,1647,962 \mathrm{~cm}^{-1} ;{ }^{1} \mathrm{H}$ and ${ }^{13} \mathrm{C}$ NMR: See Table 1; (+)-HRESIMS $m / z$, $479.2899[\mathrm{M}+\mathrm{H}]^{+}$(calc. for $\mathrm{C}_{29} \mathrm{H}_{39} \mathrm{~N}_{2} \mathrm{O}_{4}{ }^{+}, 479.2904$ ).

28- $N$-methylikarugamycin (2): White amorphous solid; $[\alpha]^{25} \mathrm{D}+141.3$ (c $\left.0.01, \mathrm{CHCl}_{3}\right)$; UV (DAD) $\lambda_{\max } 228,330 \mathrm{~nm}$; IR (ATR) $v_{\max } 3339,2953,1715,1639,939 \mathrm{~cm}^{-1} ;{ }^{1} \mathrm{H}$ and ${ }^{13} \mathrm{C}$ NMR: see Table 1; (+)-HRESIMS $m / z, 493.3063[\mathrm{M}+\mathrm{H}]^{+}$(calc. for $\mathrm{C}_{30} \mathrm{H}_{41} \mathrm{~N}_{2} \mathrm{O}_{4}{ }^{+}, 493.3061$ ).

30-oxo-28-N-methylikarugamycin (3): Pale pink amorphous solid; $[\alpha]^{25} \mathrm{D}+275.5$ (c $0.095, \mathrm{CHCl}_{3}$ ); UV (DAD) $\lambda_{\max } 228,335 \mathrm{~nm}$; IR (ATR) $\nu_{\max } 3341,2918,1704,1636,989 \mathrm{~cm}^{-1} ;{ }^{1} \mathrm{H}$ and ${ }^{13} \mathrm{C}$ NMR: See Table 1; (+)-HRESIMS $m / z$ 507.2859 [M + H] $]^{+}$(calc. for $\mathrm{C}_{30} \mathrm{H}_{39} \mathrm{~N}_{2} \mathrm{O}_{5}{ }^{+}, 507.2854$ ).

\subsection{Antifungal and Antibacterial Assays}

Compounds 1-7 were tested for their ability to inhibit the growth of key fungi (A. fumigatus ATCC46645), yeast (C. albicans MY1055) and bacteria (E. coli MB2884 and meticillin-resistant S. aureus MB5393) following a previously described methodology [26,27]. Briefly, each compound 
was serially diluted in DMSO with a dilution factor of 2 to provide 10 concentrations starting at $64 \mu \mathrm{g} / \mathrm{mL}$ for all the assays. The MIC was defined as the lowest concentration of an antibacterial or antifungal compound that inhibited $\geq 95 \%$ of the growth of a microorganism after overnight incubation. The Genedata Screener software (version 11.0.3, Genedata, Inc., Basel, Switzerland) was used to process and analyze the data and also to calculate the RZ' factor which predicts the robustness of an assay [28]. In all experiments performed in this work the RZ' factor obtained was between 0.87 and 0.98 .

\section{Conclusions}

Ikarugamycin and three new bioactive polycyclic tetramate macrolactams 1-3 have been identified from the culture of an actinomycete strain closely related to Streptomyces zhaozhouensis NEAU-LZS-5(T), isolated from a marine sediment sample collected in Equatorial Guinea. Compounds 1-2 caused strong inhibition of the growth of methicillin-resistant $S$. aureus, $C$. albicans and A. fumigatus, with MIC values in the micromolar range. MIC values obtained for the series of PTMs suggest that whereas $\mathrm{N}$-methylation of the nitrogen atom of the tetramic acid moiety does not affect the antibacterial and antifungal activity of the compounds, the presence of a carbonyl group in the ethyl side chain at C-16 causes a severe decrease in the MIC revealing that the presence of the ethyl group plays a key role in the biological activity of this family of molecules. This article constitutes the first report on the chemical composition of extracts from a marine strain closely related to the recently described terrestrial species S. zhaozhouensis [4] and confirms that marine derived actinomycetes continue to be a rich and underexploited source of new small molecules that could lead to the discovery of new antibiotics.

\section{Acknowledgments}

The authors acknowledge the assistance of C. Moreno and F. Muñoz in the preparation of extracts, M. Estévez for assistance in the fermentation of the strain, and J. Martín for recording and interpreting the ESI-TOF spectra. This project has received funding from the European Union's Seventh Framework Programme for research, technological development and demonstration under grant agreement No. 312184. The polarimeter, HPLC, IR and NMR equipment used in this work were acquired with two grants for scientific and technological infrastructures from the Ministerio de Ciencia e Innovación (Grants No. PCT-010000-2010-4 (NMR) and INP-2011-0016-PCT-010000-ACT6 (Polarimeter, HPLC and IR)).

\section{Author Contributions}

RL and CG performed the extraction of the culture broths and the isolation of the compounds. DOC carried out the fermentation and the taxonomic identification of the microbial strain. CD, MC and FV performed the antibacterial and antifungal assays. RL and IPV analyzed the spectroscopic data and elucidated the structure of the new molecules. FR, OG and FV conceived the research and supervised the work. RL, DOC, OG and FR wrote the paper, which was revised and approved by all the authors. 


\section{Conflicts of Interest}

The authors declare no conflict of interest.

\section{References}

1. Jensen, P.R.; Mincer, T.J.; Williams, P.G.; Fenical, W. Marine actinomycete diversity and natural product discovery. Antonie Leeuwenhoek 2005, 87, 43-48.

2. Gerwick, W.H.; Moore, B.S. Lessons from the past and charting the future of marine natural products drug discovery and chemical biology. Chem. Biol. 2012, 19, 85-98.

3. Manivasagana, P.; Venkatesan, J.; Sivakumar, K.; Kim, S. Pharmaceutically active secondary metabolites of marine actinobacteria. Microbiol. Res. 2014, 169, 267-278.

4. Hairong, H.; Chongxi, L.; Junwei, Z.; Wejun, L.; Tong, P.; Lingyu, Y.; Xiangjing, W.; Wensheng, X. Streptomyces zhaozhuensis sp. nov., an actinomycete isolated from candelabra aloe (Aloe arborescens Mill). Int. J. Syst. Evol. Microbiol. 2014, 64, 1096-1101.

5. Jomon, K.; Kuroda, Y.; Ajisaka, M.; Sakai, H. A new antibiotic, Ikarugamycin. J. Antibiot. 1972, $25,271-280$

6. Ito, S.; Hirata, Y. The structure of Ikarugamycin, an acyltetramic acid antibiotic possessing a unique as-hydrindacene skeleton. B. Chem. Soc. Jpn. 1977, 50, 1813-1820.

7. Blodgett, J.A.V.; Oh, D.-C.; Cao, S.; Currie, C.R.; Kolter, R.; Clardy, J. Common biosynthetic origins for polyciclic tetramate macrolactams from phylogenetically diverse bacteria. Proc. Natl. Acad. Sci. USA 2010, 107, 11692-11697.

8. Yu, F.; Zaleta-Rivera, K.; Zhu, X.; Huffman, J.; Millet, J.C.; Harris, S.D.; Yuen, G.; Li, X.-C.; $\mathrm{Du}, \mathrm{L}$. Structure and biosynthesis of heat-stable antifungal factor (HSAF), a broad-spectrum antimycotic with a novel mode of action. Antimicrob. Agents Chemother. 2007, 51, 64-72.

9. Kanazawa, S.; Fusetani, N.; Matsunaga, S. Cylindramide: Cytotoxic tetramic acid lactam from the marine sponge Halichondria cylindrata Tanita \& Hoshino. Tetrahedron Lett. 1993, 34, 1065-1068.

10. Shigemori, H.; Bae, M.A.; Yazawa, K.; Sasaki, T.; Kobayashi, J. Alteramide A, a new tetracyclic alkaloid from a bacterium Alteromonas sp. associated with the marine sponge Halichondria okadai. J. Org. Chem. 1992, 57, 4317-4320.

11. Gunasekera, S.P.; Gunasekera, M.; McCarthy, P. Discodermide: A new bioactive macrocyclic lactam from the marine sponge Discodermia dissoluta. J. Org. Chem. 1991, 56, 4830-4833.

12. Kim, O.S.; Cho, Y.J.; Lee, K.; Yoon, S.H.; Kim, M.; Na, H.; Park, S.C.; Jeon, Y.S.; Lee, J.H.; $\mathrm{Yi}, \mathrm{H}$; et al. Introducing EzTaxon: A prokaryotic 16S rRNA Gene sequence database with phylotypes that represent uncultured species. Int. J. Syst. Evol. Microbiol. 2012 62, 716-721.

13. Jukes, T.H.; Cantor, C. Evolution of protein molecules. In Mammalian Protein Metabolism; Munro, H.N., Allison, J.B., Eds.; Academic Press: New York, NY, USA, 1969; pp. 121-132.

14. Saitou, N.; Nei, M. The neighbor-joining method: A new method for reconstructing phylogenetic trees. Mol. Biol. Evol. 1987, 4, 406-425.

15. Zink, D.; Dufresne, C.; Liesch, J.; Martín, J. Automated LC-MS analysis of natural products: Extraction of UV, MS and retention time data for component identification and characterization. 
In Proceedings of the 50th ASMS Conference on Mass Spectrometry and Allied Topics, Orlando, FL, USA, 2-6 June 2002.

16. Zink, D.; Dufresne, C.; Liesch, J.; Martín, J. Identification/dereplication of natural products by LC-UV-MS. In Proceedings of the Spectral Search Parameters Presented at the Small Molecule Science Conference (COSMOS), Bristol, RI, USA, 8-11 August 2005.

17. Martín, J.; Pérez-Victoria, I.; González, V.; de Pedro, N.; Vicente, F.; Bills, G.; Reyes, F. Applying LC-MS de-replication strategies for the discovery of new natural products. Planta Med. 2012, 78, PI77.

18. Zhang, G.; Zhang, W.; Zhang, Q.; Shi, T.; Ma, L.; Zhu, Y.; Li, S; Zhang, H; Zao, Y-L.; Shi, R.; et al. Mechanistic insights into polycycle formation by reductive cyclization in ikarugamycin biosynthesis. Angew. Chem. Int. Ed. 2014, 53, 4840-4844.

19. Cho, K.; Lee, H.; Rho, J.; Kim, T.; Mo, S.; Shin, J. New lactone containing metabolites from marine-derivade bacterium of the genus Streptomyces. J. Nat. Prod. 2001, 64, 664-667.

20. Maskey, R.P.; Pusecker, K.; Speitling, M.; Monecke, P.; Helmke, E.; Laatsch, H. 2 "-Chartreusin-monoacetate, a new natural product with unusual anisotropy effects from the marine isolate Streptomyces sp. B5525, and its 4"-isomer. Z. Naturfosch 2002, 57b, 823-829.

21. Wratten, S.J.; Wolfe, M.S.; Andersen, R.J.; Faulkner, D.J. Antibiotic metabolites from a marine pseudomonad. Antimicrob. Agents Chemother. 1977, 11, 411-414.

22. Antosch, J.; Schaefers, F.; Gulder, T.A.M. Heterologous reconstitution of ikarugamycin biosynthesis in E. coli. Angew. Chem. Int. Ed. 2014, 53, 3011-3014.

23. Kyeremeh, K.; Acquah, S.; Sazak, A.; Houssen, W.; Tabudravu, J.; Deng, H.; Jaspars, M. Butremycin, the 3-hydroxyl derivative of ikarugamycin and a protonated aromatic tautomer of 5'-methylthioinosine from a ghanaian Micromonospora sp. K310. Mar. Drugs 2014, 12, 999-1012.

24. Hasegawa, H.; Sato, J.; Asaoka, T.; Nakajima, T. Ikarugamycin Derivative. Jpn. Patent JPS 6345280, 26 February, 1988.

25. Cao, S.; Blodgett, J.A.V.; Clardy, J. Targeted discovery of polycyclic tetramate macrolactams from an environmental Streptomyces strain. Org. Lett. 2010, 12, 4652-4654

26. Martín, J.; da S. Sousa, T.; Crespo, G.; Palomo, S.; González, I.; Tormo, J.R.; de la Cruz, M.; Anderson, M.; Hill, R.T.; Vicente, F.; et al. Kocurin, the true structure of PM181104, an anti-methicillin-resistant Staphylococcus aureus (MRSA) thiazolyl peptide from the marine-derived bacterium Kocuria palustris. Mar. Drugs 2013, 11, 387-398.

27. Monteiro, M.C.; de la Cruz, M.; Cantizani, J.; Moreno, C.; Tormo, J.R.; Mellado, E.; de Lucas, J.R.; Asensio, F.; Valiante, V.; Brakhage, A.A.; et al. A new approach to drug discovery: High-throughput screening of microbial natural extracts against Aspergillus fumigatus using resazurin. J. Biomol. Screen. 2012, 17, 542-549.

28. Zhang, J.H.; Chung, T.D.; Oldenburg, K.R. A simple statistical parameter for use in evaluation and validation of high throughput screening assays. J. Biomol. Screen. 1999, 4, 67-73.

(C) 2014 by the authors; licensee MDPI, Basel, Switzerland. This article is an open access article distributed under the terms and conditions of the Creative Commons Attribution license (http://creativecommons.org/licenses/by/4.0/). 